
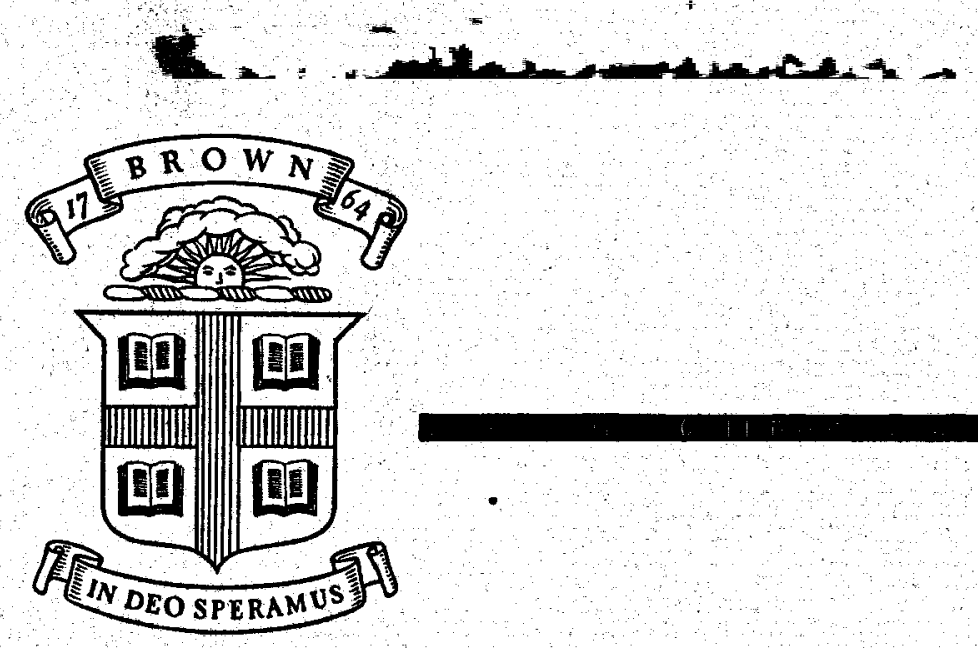

\title{
TWO-PHASE FLOW IN
} HORIZONTAL PIPES

P. F. Maeder, E. E. Michaelides and R. DiPippo

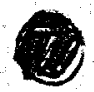 \\ University of California \\ Los Alamos National Laboratory \\ LASL 4-X60-6306P-1
}




\section{DISCLAIMER}

This report was prepared as an account of work sponsored by an agency of the United States Government. Neither the United States Government nor any agency Thereof, nor any of their employees, makes any warranty, express or implied, or assumes any legal liability or responsibility for the accuracy, completeness, or usefulness of any information, apparatus, product, or process disclosed, or represents that its use would not infringe privately owned rights. Reference herein to any specific commercial product, process, or service by trade name, trademark, manufacturer, or otherwise does not necessarily constitute or imply its endorsement, recommendation, or favoring by the United States Government or any agency thereof. The views and opinions of authors expressed herein do not necessarily state or reflect those of the United States Government or any agency thereof. 


\section{DISCLAIMER}

Portions of this document may be illegible in electronic image products. Images are produced from the best available original document. 


\title{
TWO-PHASE FLOW IN HORIZONTAL PIPES
}

by

P. F. Maeder, E. E. Michaelides ${ }^{(1)}$ and R. DiPippo ${ }^{(2)}$

\author{
Division of Engineering \\ Brown University \\ Providence, R.I. 02912
}

Sept ember 1981

(1) Dept. of Mechanical \& Aerospace Engineering, University of Delaware, Newark, DE.

(2) Dept. of Mechanical Engineering, Southeastern Massachusetts University N. Dartmouth, MA. 
CONTENTS

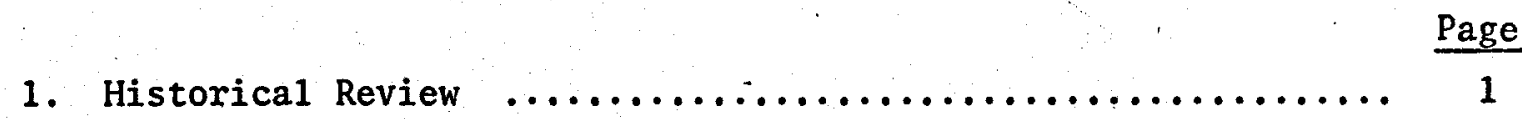

2. Formulation of the Problem Statement $\ldots \ldots \ldots \ldots \ldots \ldots \ldots \ldots \ldots$

3. Shear Stresses $\ldots \ldots \ldots \ldots \ldots \ldots \ldots \ldots \ldots \ldots \ldots \ldots \ldots \ldots \ldots \ldots$

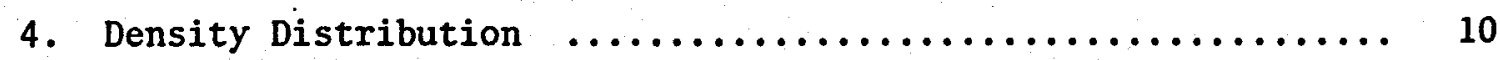

5. Working Equations $\ldots \ldots \ldots \ldots \ldots \ldots \ldots \ldots \ldots \ldots \ldots \ldots \ldots \ldots \ldots \ldots$

5.1 Velocity profile $\ldots \ldots \ldots \ldots \ldots \ldots \ldots \ldots \ldots \ldots \ldots \ldots \ldots \ldots$

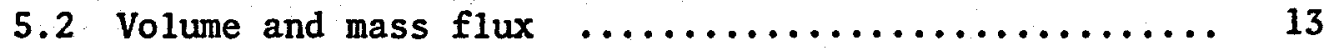

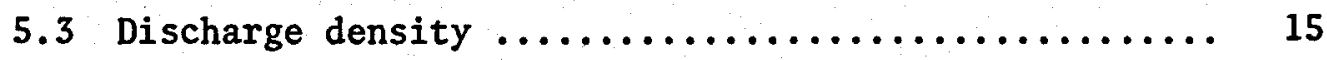

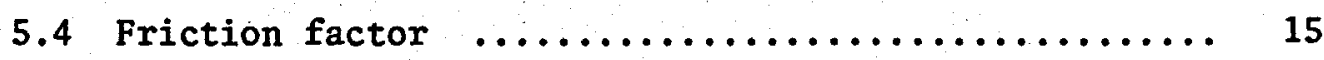

6. Entropy Production and Pressure Drop in the Pipe $\ldots \ldots \ldots \ldots$

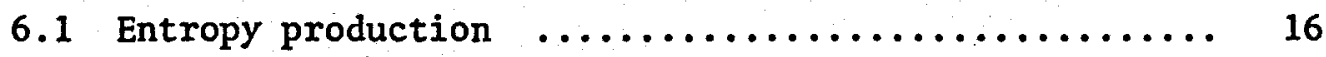

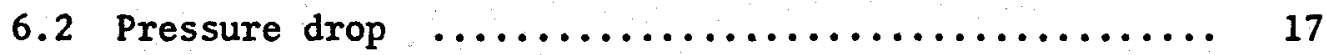

7. Determination of Parameters and Solution of the Equations ... 18

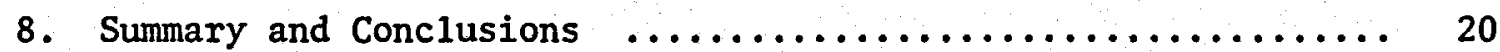

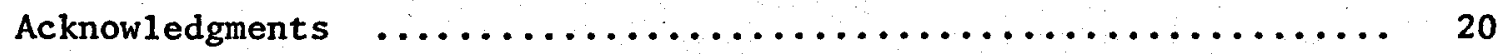

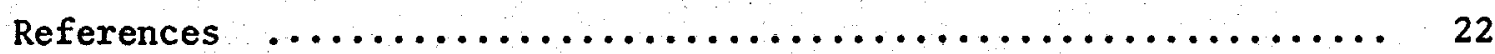

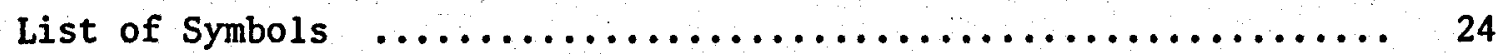

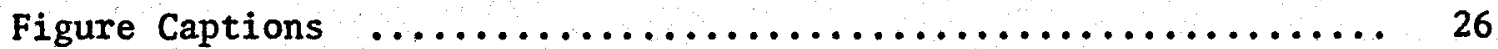

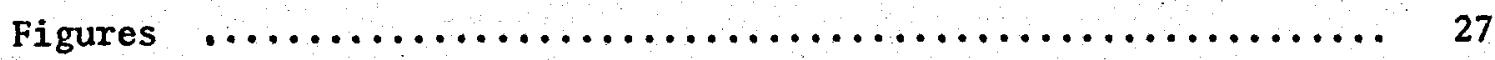




\section{Historical Review}

The literature contains an abundance of papers dealing with analytical and empirical relationships for the pressure drop in two-phase flows through pipes [1]. The earliest attempts were based mainly on empirical correlations of experimental observations. For example, Martinelli's theories, first published in the late forties $[2,3]$ are empirical correlations of the pressure drop in horizontal pipes using similarity laws. Although these correlations are still applied to many engineering problems, they suffer from deficiencies in many cases.

Improved correlations have since been developed, with the purpose of increasing the accuracy of the results. The so-called "homogeneous model", on the one hand, was developed on the assumption of constant density and velocity across the pipe [4]. The so-called "separated models", on the other hand, use the average velocity and density for each phase and the conservation equations applied separately to each phase. In this latter model, the notion of "slip" is introduced to account for the ratio of the vapor to liquid average velocities $[5,6]$. The separated models were an improvement over the older theories, but likewise have proved inaccurate in many cases, with deviations from experimental results being as high as $80 \%$.

One of the shortcomings of these models is that they require additional assumptions about the pressure drop, mainly derived from experimental data. The major deficiency of these methods, however, lies in the fact that they do not describe the local variation across the pipe of quantities such as density and velocity. Thus, even if they successfully predict the pressure distribution over some length of the pipe, they fail to account for phenomena that depend on the local quantities. 
The so-called "pattern mode1s", developed in the sixties, improve some of the deficiencies of the above methods by taking into consideration the local variation of density and velocity. The conservation equations are solved on the assumption of predetermined geometric patterns of flow (e.g., bubbly, slug, froth; and annular). The resulting equations are complicated and their solution requires special assumptions that restrict the applicability of the theories. This category includes Mendelson's for bubbly flow [7], Griffith's and Wallis's for slug flow [8], and Levy's for annular flow [9]. Bankoff's model [10] of continuous density and velocity distributions may also be included in this categpry.

All of the above methods seem to be based on the same principle, namely, that two-phase flow should be treated in the same way as single-phase flow. The following simple analogy may be drawn. In single-phase flow with constant area, the pressure gradient is given by the expression:

$$
\frac{d p}{d x}=\frac{f_{S P}}{2 D \rho_{f}}\left(\frac{\dot{m}}{A}\right)^{2} \text {. }
$$

In order to extend this to the case of two-phase flow where the wall is wet, only two changes are required: (1) the liquid phase now carries a mass flow rate equal to $\dot{m}(1-\gamma)$, and (2) it occupies an area $A(1-\phi)$. Here, $\gamma$ denotes the dryness fraction (or quality) and $\phi$ is the void fraction. Accordingly, the pressure drop in two-phase flow may be written as:

$$
\frac{d p}{d x}=\frac{f_{S P}}{2 D \rho_{f}}\left(\frac{\dot{m}}{A}\right)^{2}\left(\frac{1-\gamma}{1-\phi}\right)^{2}
$$

This analogy between single- and two-phase flow is depicted schematically in Fig. 1 .

Unfortunately when eq. (2) is confronted by experiment, it is found that the pressure gradients are much higher than the ones observed in 
reality. The void fraction was then modified in an attempt to give better results. The concept of slip was introduced and correlations were developed that matched the void fraction (or, equivalently, the slip) with the observed pressure drop.

An attempt was made by Levy [11] to change the approach to this subject. He introduced a model based on PrandtI's mixing-length theory [12], and by so doing made a valuable contribution to the theory of two-phase flouz. The results obtained by his work, however, do not agree well with experiment, as indicated in Hughmark's discussion of the paper. The present authors feel that this is due to the particular choice of the density distribution and the closure equation for the shear stress which in fact turn out to violate the second law of thermodynamics. The density distribution taken from Pai [13] leads to constant density along streamlines, as was pointed out by Corrsin in the discussion of Pai's paper. This implicit assumption of constant density is trivial for the pipe flow problem and does not furnish information regarding the density distribution across the pipe.

A different approach to the subject is proposed in this paper. The flow quantities are taken as the local, time-averaged quantities as derived from the Navier-Stokes equations. Thus the averaged effect of fluctuations (i.e., Reynolds stresses) is incorporated in the equations. The time-averaging procedure simplifies the equations considerably and has given accurate results, for example, in the case of turbulent flow. In view of the fact that we are interested in the time-averaged pressure drops and entropy production, it seems that this method is appropriate. This approach uses the same assumptions as does the mixing length theory applied to compressible flow problems. In particular, the medium is treated as a continuum of variable density, and the flow quantities vary both 
across and along the pipe.

\section{Formulation of the Problem Statement}

This study examines adiabatic flow in a pipe of a single-component fluid in which both liquid and vapor phases may be present in the absence of body forces, i.e., in a horizontal pipe. The problem occurs, for example, in the flow of a geothermal fluid through the piping network and various components of a geothermal power plant.

The approach taken in this study is predicated on the assumption that thermodynamic equilibrium prevails in the fluid, and that the pressure is constant across the pipe. Thus, the temperature must also be constant at any cross-section. Ali thermodynamic properties may be obtained from the normal equilibrium relations.

The time-averaged Navier-Stokes equations with Reynolds stresses included will be developed. If the boundary conditions do not vary appreciably in one direction, then the problem will possess two length scales, one very much larger than the other. Changes in fluid properties will be much more gradual in the longitudinal direction (i.e., along the pipe) than in the transverse direction (i.e., across the pipe). Thus, with the exception of the pressure gradient, $\mathrm{dp} / \mathrm{dx}$, all derivatives in the longitudinal direction are neglected. The longitudinal changes in the other fluid properties are introduced later with no appreciable loss in accuracy.

In order to solve the problem one must introduce the density distribution and a closure condition for the shearing stress. It is an empirical fact that in adiabatic flows of this kind, the wall of the pipe is always wet. Accordingly the density distribution is chosen such that the value for the liquid density is attained at the wall. 
The basic governing equations, written in vectorial form, are:

$$
\rho \frac{\overrightarrow{\mathrm{u}}}{\mathrm{Dt}}=-\overrightarrow{\mathrm{p}}+\mu \nabla^{2} \overrightarrow{\mathrm{u}}
$$

where

$$
\vec{u}=\vec{u}(r),
$$

and

$$
\mathrm{dp} / \mathrm{dr}=0
$$

Thus, we obtain

$$
\frac{\mathrm{dp}}{\mathrm{dx}}=\frac{\mu}{\mathrm{r}} \frac{\mathrm{d}}{\mathrm{dr}}\left[\mathrm{r} \frac{\mathrm{du}}{\mathrm{dr}}\right]-\frac{1}{\mathrm{r}} \frac{\mathrm{d}}{\mathrm{dr}}\left(\mathrm{r} \tau^{\prime}\right)
$$

in which $T^{\prime}$ is the Reynolds stress.

In the next two sections we discuss the shear stress terms and the density distribution needed to solve the basic Navier-Stokes equation.

\section{Shear Stresses}

Schlichting [14] and $\mathrm{Pai}$ [15] have shown that the apparent stress in the case of variable density flow is given by

$$
\tau^{\prime}=\overline{\left(u+u^{\prime}\right)\left(\rho+\rho^{\prime}\right)\left(v+v^{\prime}\right)},
$$

where $u, \rho$ and $v$ are average quantities and $u^{\prime}, \rho^{\prime}$ and $v^{\prime}$ are the corresponding turbulent fluctuations. For the case of one-dimensional pipe flow $(i, e ., v=0)$, eq. (6a) becomes

$$
\tau^{\prime}=\overline{u^{\prime} v^{\prime}}+\overline{u \rho^{\prime} v^{\prime}}+\overline{\rho^{\prime} u^{\prime} v^{\prime}} .
$$

The last term in eq. (6b) is usually neglected because it is the product of three small fluctuation terms, and thus is one order lower in magnitude than the first two terms. Therefore we write

$$
\tau^{\prime}=\overline{\rho u^{\prime} v^{\prime}}+\overline{u \rho^{\prime} v^{\prime}},
$$

and observe that the apparent stress is comprised of two momentum exchange 
terms, one stemming from velocity fluctuations and one caused by the combined effect of velocity and density fluctuations.

Furthermore the apparent stress, usually called the Reynolds stress, must also satisfy the dissipation inequality

$$
\tau, \frac{d u}{d y} \geq 0,
$$

which states that the apparent stress acts in the direction of the velocity gradient.

The shear stress of the fluid at any radial location is given by the sum of the viscous and the turbulent components

$$
\tau=\mu \frac{d u}{d y}+\tau^{\prime}
$$

The system of coordinates chosen for this problem is shown in Fig. 2. It can be seen that

$$
y=r_{0}-r
$$

and represents the distance from the pipe wall into the fluid. The fluid is divided into a laminar sublayer, where the flow is predominantly laminar, and a turbulent region where turbulence dominates. The latter area extends from the center of the pipe, i.e., from $y=r_{0}$ to $y=y_{0}$, with the laminar sublayer continuing from $y=y_{0}$ to $y=0$ (or $\left.r=r_{0}\right)$. It is generally accepted that the viscous stress $\mu(\mathrm{du} / \mathrm{dy})$ is the main component of $\tau$ in the laminar sublayer and that the Reynolds stress $\tau^{\prime}$ is the predominant form of stress in the turbulent region:

$$
\begin{array}{ll}
\tau \approx \mu \frac{\mathrm{du}}{\mathrm{dy}}, & \mathrm{r}_{0} \geq y \geq y_{0} ; \\
\tau \approx \tau, & \mathrm{y}_{0} \geq y \geq 0
\end{array}
$$

The value of $y_{0}$ separating the two regions will be fixed later.

The stress distribution across the pipe is linear, with the shear stress 
being zero at the center of the pipe and having its maximum value $\tau_{w}$ at the wall. The equilibrium of the forces acting at any radius $r$ of the pipe (neglecting the acceleration) is given as follows:

$$
r \tau=-\frac{r^{2}}{2} \frac{d p}{d x}
$$

In particular; at the wall, the pressure gradient is given by

$$
\left.\frac{d p}{d x}\right|_{w}=-\frac{2}{r_{0}} \tau_{w}
$$

Since the laminar sublayer is very small in comparison with the radius of the pipe, it is often assumed that the apparent stress at $y_{0}$ is equal to the wall shear stress $\tau_{w}$ :

$$
\tau_{w} \simeq \tau\left(y_{0}\right)=\tau^{\prime}\left(y_{0}\right)=\rho_{f} V^{* 2},
$$

where $\mathrm{V}^{*}$ is the so-called "shear velocity" I14] of the flow, defined in terms of $\tau_{w}$ by eq. (14). The shear velocity is a ficticious velocity related to the velocity gradient in the fluid rather than the velocity itself. The relationship between $V^{*}$ and the velocity gradient will be made clear later in this section. The shear distribution across the pipe has a linear form and may be expressed as follows:

$$
\tau=\tau_{W}\left(1-\frac{y}{r_{o}}\right)=\rho_{f} V^{* 2}\left(1-\frac{y}{r_{o}}\right)
$$

A closure equation is necessary for the apparent stress $\tau$ ', since it is not possible to calculate it in terms of the velocity fluctuations as given in eq. (6c). The closure equation is subject to the constraint of ineq. (7) for positive entropy production. In single-phase flow, first Prandtl's mixing length theory [12] and later von Karman's similarity hypothesis [16] provided this closure equation. Prandt1 [12] and Taylor [17] showed that the first term in eq. (6c) for the apparent stress could 
be written as

$$
\rho \overline{u^{\prime} v^{\prime}}=\rho \ell_{u}^{2}\left|\frac{d u}{d y}\right| \frac{d u}{d y}
$$

where the velocity fluctuations have been taken proportional to $|\mathrm{du} / \mathrm{dy}|$. The reader may wish to consult references [12] and [17] for the physical reasoning that guided Prandtl and Taylor. Similarly one may take the density fluctuations as proportional to the density gradient:

$$
\rho^{\prime}=\ell_{\rho}\left|\frac{\mathrm{d} \rho}{\mathrm{dy}}\right| \text {. }
$$

This leads to the following expression for the second term in eq. (6c):

$$
u \overline{\rho^{\prime} v^{\prime}}=\ell_{\rho} \ell_{u}\left|\frac{d \rho}{d y}\right| \frac{d u}{d y} .
$$

As a first hypothesis we may assume that the two unknown "mixing lengths", $\ell_{u}$ and $\ell_{\rho}$, are equal:

$$
\ell_{u}=\ell_{\rho} \equiv \ell .
$$

Note that this is not without loss of generality since we are, in general, not free to combine the two length scales into one. Thus, the expression for the apparent stress, taking into account both density and velocity fluctuations in the fluid, may be written in the form

$$
\tau^{\prime}=e^{2}\left[\rho\left|\frac{d u}{d y}\right|+u\left|\frac{d \rho}{d y}\right|\right] \frac{d u}{d y}
$$

Prandt 1 , observing that the mixing length $\ell$ must be zero at the wall and must be related to some other length in the problem proposed the simplest possible expression for this relationship, namely:

$$
\ell=k y \text {, }
$$


since $y$ is the only other physical length in the problem. This expression is preferred over other more complicated ones [16] which, nevertheless, give very similar velocity distributions for single-phase flow.

The apparent shear stress $\tau$ ' can now be written in terms of "boundary layer" coordinates:

$$
\tau^{\prime}=\kappa^{2}\left[\rho_{f}\left|\frac{d u}{d \eta}\right|+\left|u \frac{d \rho}{d \eta}\right|\right] \frac{d u}{d \eta},
$$

where,

$$
n=\ln \left(y / y_{0}\right)
$$

Since the velocity profile varies continuously from a value of zero at the wall to a maximum value on the centerline of the pipe, the question of how to determine the length $y_{0}$ must be answered. The velocity of the fluid at the wall is zero because of the intermolecular forces of the fluid particles and those of the wall. Given that the velocity function is continuous, the fluid must attain low velocities near the wall; hence the flow there must be laminar in the case of smooth pipes for it is dominated by the surface roughness), In this region the velocity profile is linear according to the equation:

$$
u^{+}=y v^{*} / v_{f}
$$

At distances farther from the wall, a transition region develops where the turbulent effects are of the same order of magnitude as the laminar effects; even farther away, purely turbulent stresses predominate. For the latter case, the velocity distribution has been found from single-phase flow experiments to be given by the following equation:

$$
u^{+}=2.5 \ln \left(y^{*} / v_{f}\right)+5.5 \quad \text { for smooth pipes, }
$$

and

$$
u^{+}=2.5 \ln (y / k)+8.5 \quad \text { for rough pipes. }
$$


In these equations, $\nu_{f} / V^{*}$ plays the role of a characteristic viscous length, and $k$ is a characteristic roughness length. The region of turbulence is characterized by the value $y=y_{0} \quad($ or $n=0)$; the combinations of eq. (24) with eq. (25) and (26) yield, respectively:

$$
y_{0}=0.111 v_{f} / V^{*} \quad \text { for smooth pipes, }
$$

and

$$
y_{0}=0.0344 k \quad \text { for rough pipes. }
$$

The two expressions above may be added together to give an expression for commercial pipes:

$$
y_{0}=0.111 k\left(\nu_{f} / k^{*}+0.3\right)
$$

It is seen that when $\nu_{f} / \mathrm{kV}^{*}<0.3$, roughness effects predominate and the pipe is characterized as "rough"; in the opposite case, the pipe is classified as "smooth". For purposes of integration over the boundary layer coordinates we shall need the upper limit of $n$ which we designate $n^{*}$. This will be attained when $y=r_{0}$ in eq. (23); thus,

$$
\begin{aligned}
n^{*} & =\ln \left(r_{0} / y_{0}\right) \\
& =\ln \left(r_{0} / k\right)+2.198-\ln \left(\nu_{f} / k v^{*}+0.3\right)
\end{aligned}
$$

where use has been made of the combined expression for $y_{0}$, eq. (29).

\section{Density Distribution}

The flows of interest for the present study are those in which the liquid phase is predominate in the mass balance. Such flows are characterized by a contiguity of the liquid phase, which encloses the vapor fraction. Consequently, the walls of the pipe are always wet and layers of higher-thanaverage density appear near the wall. All flow regimes fit this category 
except mist and stratified flow which are not covered by the present analysis.

In general the time-averaged density distribution function will depend on both spatial coordinates $x$ and $y$, i.e., $\rho=\rho(x, y)$. The longitudinal variation in $\rho$ is caused by the evaporation of liquid as the static pressure in the fluid falls. The transverse variation in $\rho$ is caused by the presence of vapor in the core of the flow. These considerations suggest that $\rho(x, y)$ should have the value $\rho_{f}$ at the wall (i.e., at $y=0$ ), and should be monotonically decreasing with y. Owing to the entrainment of liquid droplets in the bulk vapor flow, the density on the centerline (i.e., at $y=r_{0}$ ) should be somewhat larger than the vapor density. These constraints on $\rho(x, y)$ are based on experimental observations.

For this study we have selected a simple function for the density distribution that conforms to the above constraints, namely:

$$
\rho(x, y)=\rho_{f}\left[1+\alpha(x) \eta(y) / n^{*}\right]^{-2 m} \quad(m \geq 0),
$$

with the restriction

$$
\rho_{g} / \rho_{f} \leq[1+\alpha(x)]^{-2 m}
$$

It must be emphasized that eq. (31) applies only in the variable-density portion of the flow, i.e., from $y=y_{0}$ to $y=r_{0}$ (or from $n=0$ to $n=n^{*}$ ). Furthermore we postulate that the density in the laminar sublayer is constant and equal to $\rho_{f}$. The value of $\alpha(x)$ will account for the entrainment of liquid droplets in the vapor.

Some average flow quantities of practical significance can now be derived from this density distribution. In particular the local void fraction $\phi(x, y)$ is given as follows:

$$
\phi(x, y)=\frac{\left(1+\alpha \eta / \eta^{*}\right)^{-2 m}-1}{\left(\rho_{g} / \rho_{f}\right)-1}
$$


One may obtain the spatially-averaged void fraction $\phi(x)$ at any crosssection by integrating eq. (33) across the pipe. Likewise the spatiallyaveraged density $\bar{\rho}$ is given by the integral

$$
\bar{\rho}=\int_{0}^{\eta^{*}} \rho_{f}\left(1+\alpha \eta / \eta^{*}\right)^{-2 m}\left[1-e^{\left(\eta-\eta^{*}\right)}\right] e^{\left(\eta-\eta^{*}\right)} d \eta
$$

By definition, the average void fraction and average density are related through the expression

$$
\bar{\rho}=(1-\phi) p_{f}+\phi p_{g}
$$

For given (or assumed) values of $\mathrm{m}$ and $\phi$, eqs. (34) and (35) may be solved simultaneously to yield the coefficient $\alpha$.

\section{Working Equations}

\subsection{Velocity profile}

The equations developed in Sect. 3 for the shear stress and velocity distribution may be written in final form in terms of the shear velocity as follows:

$V *^{2}\left[1-e^{\left(n-n^{*}\right)}\right]=k^{2}\left\{\left(1+\alpha \eta / n^{*}\right)^{-2 m}\left|\frac{d u}{d \eta}\right|+2|u|\left(\alpha m / n *\left(1+\alpha n / n^{*}\right)^{-2 m-1}\right\} \frac{d u}{d n}\right.$.

We may use a dimensionless velocity, $u^{+}$, (see eq. (24)) defined as

$$
u^{+}=u / v^{*},
$$

and transform eq. (36) into a dimensionless form:

$$
1-e^{\left(n-n^{*}\right)}=k^{2}\left\{\left(1+\alpha \eta / n^{*}\right)^{-2 m}\left|\frac{d u^{+}}{d \eta}\right|+2\left|u^{+}\right|\left(\alpha m / n^{*}\right)\left(1+\alpha n / n^{*}\right)^{-2 m-1}\right\} \frac{d u^{+}}{d \eta} .
$$

For the sake of convenience we define two functions, $F_{1}(n)$ and $F_{2}(n)$, in order to shorten the above expression and to simplify the computations: 


$$
F_{1}(\eta) \equiv\left(1+\alpha \eta / n^{*}\right)^{2 m}\left[1-e^{\left(\eta-\eta^{*}\right)}\right] / \kappa^{2}
$$

and

$$
\begin{aligned}
F_{2}(n) & \equiv\left(2 \alpha m / n^{*}\right)\left(1+\alpha \eta / \eta^{*}\right)^{-1} \\
& =2 \alpha m /\left(\eta^{*}+\alpha \eta\right) \\
& =\frac{d}{d \eta}\left[\ln \left(\rho_{f} / \rho\right)\right]
\end{aligned}
$$

where eq. (31) has been used to obtain eq. (40c).

Now eq. (38) can be written in a simpler form in terms of the functions $F_{1}$ and $F_{2}$ :

$$
\left|\frac{d u^{+}}{d \eta}\right| \frac{d u^{+}}{d \eta}+\left|u^{+}\right| F_{2} \frac{d u^{+}}{d \eta}-F_{1}=0 .
$$

When $u^{+} \geq 0$ and $\mathrm{du}^{+} / \mathrm{d} \eta \geq 0$, eq. (41) is a simple quadratic in the velocity gradient and may be solved straightforwardly to give:

$$
\frac{\mathrm{du}^{+}}{\mathrm{dn}}=\left[\mathrm{F}_{1}+\left(\mathrm{F}_{2} \mathrm{u}^{+}\right)^{2} / 4\right]^{1 / 2}-\mathrm{F}_{2} \mathrm{u}^{+} / 2
$$

Given the form of the function $F_{1}$, this formula will always yield positive values for the velocity gradient.

The solution of the above differential equation gives the form of the velocity profile. The velocity vanishes at the boundary, $y=0$ (see Fig. 3). Equation (42) is a nonlinear differential equation that can be solved numerically; the Runge-Kutta method and Simpson's rule were used for that purpose. The determination of the velocity distribution together with the known density distribution leads to all the flow quantities of interest.

\subsection{Volume and mass flux}

For the case of pipe flow, there are mainly two rate quantities of interest to the engineer; they are the volumetric flow rate per unit area, 
$q_{a}$, and the mass flux, j. These are defined as follows:

$$
q_{a}=\dot{Q} / A,
$$

and

$$
\dot{j}=\dot{m} / \mathrm{A}
$$

It can be seen that $q_{a}$ is effectively the average velocity of the fluid across the pipe, i.e.,

$$
\mathrm{q}_{\mathrm{a}}=\overline{\mathrm{u}},
$$

and as such may be evaluated according to the following integral:

$$
\begin{aligned}
\bar{u} & =\left(2 / r_{0}^{2}\right) \int_{y_{0}}^{r} u\left(r_{0}-y\right) d y \\
& =I_{1} V^{*},
\end{aligned}
$$

where $I_{1}$ stands for the integral (expressed in boundary layer coordinates):

$$
I_{1}=2 \int_{0}^{\eta^{*}} u^{+}\left[1-e^{\left(\eta-\eta^{*}\right)}\right] e^{\left(\eta-\eta^{*}\right)} d \eta
$$

In like fashion, the mass flux may be expressed in the following form:

$$
\begin{aligned}
\dot{\mathrm{m}} & =\left(2 / \mathrm{r}_{\mathrm{o}}^{2}\right) \int_{y_{0}^{\mathrm{r}}}^{\mathrm{r}} \rho \mathrm{u}\left(\mathrm{r}_{\mathrm{o}}-y\right) \mathrm{dy} \\
& =\rho_{\mathrm{f}} \mathrm{I} \mathrm{V}^{*},
\end{aligned}
$$

where

$$
I_{2}=\int_{0}^{\eta^{*}}\left(1+\alpha \eta / n^{*}\right)^{-2 m} u^{+}\left[1-e^{\left(n-n^{*}\right)}\right] e^{\left(n-n^{*}\right)} d \eta
$$




\subsection{Discharge density}

The ratio $j / q_{a}$ is called the "discharge density", $\rho_{d}$ :

$$
\begin{aligned}
\rho_{\mathrm{d}} & =\mathrm{j} / \mathrm{q}_{\mathrm{a}} \\
& =\dot{\mathrm{m}} / \dot{\mathrm{Q}} .
\end{aligned}
$$

The discharge density may be written in terms of the integrals $I_{1}$ and $I_{2}$ as follows:

$$
\rho_{\mathrm{d}}=\rho_{\mathrm{f}} \mathrm{I}_{2} / \mathrm{I}_{1}
$$

\subsection{Friction factor}

A two-phase friction factor, $f_{T P}$, may be defined analogously to the well-known single-phase friction factor, $f_{S P}$, found in basic textbooks on fluid mechanics. The wall shear stress is thus written in the form:

$$
\tau_{w}=\frac{1}{8} f_{T P} \rho_{d} q_{a}^{2}
$$

which leads to

$$
f_{T P}=8 \tau_{w} / \rho_{d} q_{a}^{2}
$$

or,

$$
f_{\mathrm{TP}}=8 / \mathrm{I}_{1} \mathrm{I}_{2}
$$

The above equations are valid in the limiting case of single-phase flow, where the integrals $I_{1}$ and $I_{2}$ become equal, i.e., $I_{1}=I_{2}=I_{0}$. The singlephase flow friction factor can be then evaluated from

$$
f_{S P}=8 / I_{0}^{2}
$$

The ratio of the two-phase to single-phase friction factors may now be given as follows:

$$
\begin{aligned}
R_{f f} & \equiv f_{T P} / f_{S P} \\
& =I_{0}^{2} / I_{1} I_{2}
\end{aligned}
$$


This ratio has an important physical meaning: If the friction factor for the single-phase (liquid) flow is known, then the shear stress in twophase (liquid-vapor) flow may be calculated since $R_{f f}$ is deriyable from the above integrals. The single-phase friction coefficient for commercial pipe is obtained from a "Moody diagram" as a function of the Reynolds number, Re. The latter is given in terms of the mass flow rate and the viscosity of the fluid:

$$
\operatorname{Re}=4 \dot{m} / \pi D \mu
$$

The definition of the viscosity for the two-phase mixture is ambiguous. Sometimes a weighted average of the liquid and vapor viscosities is taken [10], and sometimes the liquid viscosity itself is used [11]. For the present study, the liquid viscosity will be used since the single-phase friction factor will be obtained:

$$
f_{S P}=f_{S P}(R e)=f_{S P}\left(\dot{m} / \pi D \mu_{f}\right)
$$

Equations (55a), (55b) and (57) will yield the numerical value for the twophase friction factor.

\section{Entropy Production and Pressure Drop in the Pipe}

\subsection{Entropy production}

A thorough analysis of a plant utilizing a two-phase fluid in certain of its elements ought to include a so-called "Second Law analysis", i.e., one based on the exergy of the fluid at every point. In this way the direct determination of entropy production will, at the same time, give a picture of the exergy losses, along with an indication of their causes as well as the onset of choked flow. Therefore, in this study, the pressure drop in the pipe will be evaluated from the entropy production. 
In a horizontal pipe, there is only one cause of entropy production, namely, the shear between adjacent layers of fluid moving at different velocities. This is given by the following expression:

$$
\frac{\mathrm{d} \dot{S}}{\mathrm{dx}}=\dot{\mathrm{m}} \frac{\mathrm{ds}}{\mathrm{dx}}=-(1 / \mathrm{T}) \int_{0}^{\mathrm{r}} \tau \frac{\mathrm{du}}{\mathrm{dr}} 2 \pi r \mathrm{dr} .
$$

After integration by parts and some algebraic manipulation, this becomes

$$
\frac{d s}{d x}=2 \tau_{o} / T \bar{\rho} r_{o}=f_{T p} \bar{u}^{2} / 2 T D
$$

where the two-phase friction factor, $f_{T P}$, is obtained from eqs. (55a), (55b) and (57), and the average velocity from eqs. (46a), (46b) and (47).

\subsection{Pressure drop}

The change in pressure resulting from the entropy production and the acceleration of the fluid can be derived now, on the assumption that the pipe is adiabatic. In most practical cases, the pipes are well-insulated, thus essentially eliminating any heat transfer between the pipe and the surroundings. The energy equation reduces to the form:

$$
h^{\infty}=h+g z+\bar{u}^{2} / 2=\text { const. }
$$

The Gibbs equation for equilibrium flow in a horizontal pipe gives:

$$
\mathrm{dh}^{\infty}=\mathrm{Tds}+\mathrm{dp} / \overline{\mathrm{p}}+\overline{\mathrm{u}} \mathrm{d} \overline{\mathrm{u}}=0
$$

or in final form

$$
\begin{aligned}
\frac{d p}{d x} & =-\bar{\rho} T \frac{d s}{d z}-\bar{\rho} \bar{u} \frac{d \bar{u}}{d x} \\
& =-f_{T p} \bar{\rho}^{2} / 2 D-\bar{\rho} \bar{u} \frac{d \bar{u}}{d x}
\end{aligned}
$$


This expression provides us with a measure of the pressure gradient along the pipe, in terms of equilibrium quantities that can be evaluated. In this case, the static pressure may be computed numerically at any point of the pipe and the condition of thermodynamic equilibrium will yield all the quantities of interest, such as temperature, quality, enthalpy, etc.

\section{Determination of Parameters and Solution of the Equations}

The model contains four parameters, $\kappa, m, \alpha$ and $\eta^{*}$, whose values need to be determined for any particular case of two-phase flow. Unfortunately, there are no experimental data for any of these parameters for the two-phase flow case. Consequently we have decided to use single-phase data for the preliminary calculations, whenever this is possible. Thus we have selected the value $k=0.4$.

Since we found that the ratio of two-phase to single-phase friction factors turns out to be quite insensitive to the value of $n^{*}$ (a measure of the pipe Reynolds number, eq. (30b)), we present results for $\eta^{*}=8$ only.

The other parameters $\alpha$ and $m$ come in only for the variable density case, and therefore, cannot be found from past experimental work in single-phase flows. It is apparent that both of these are functions of the particular flow being studied. We are presenting calculations for $m=$ constant, and attribute to $\alpha$ alone all the variation of density in the flow direction. If either $\alpha$ or $m$ is specified, then the other is determined through the average void fraction. The space-averaged density, $\bar{\rho}$, was given in terms of $\alpha$ and $m$ in eq. (34). This density is connected to the void fraction by eq. (35), where

$$
\phi(x)=1 /\left\{1+\frac{\gamma}{\gamma-1}\left(\rho_{f} / \rho_{g}\right)\right\} .
$$


Here $\phi(x)$ is the space-averaged void fraction and $\gamma$ is the dryness fraction. Therefore, for the determination of $\alpha(\gamma, x)$ we have only to solve the integral equation (34) for every position in the pipe. Given that $\gamma$ is a function of the pressure $P(x)$, we can write $\alpha=\alpha(x)$ at every position in the pipe.

Some results of the study are presented in Fig. 4 which depicts the ratio, $R_{f f}$, of the two-phase friction factor divided by the single-phase friction factor versus the ratio of the liquid density divided by the averaged density, i.e., $f_{T P} / f_{S P}$ vs. $\rho_{f} / \rho$, with $m$ as a parameter. It is seen that $R_{f f}$ initially rises linearly with the logarithm of $\rho_{f} / \rho$, but then reaches an asymptotic value that depends on the value of $m, i . e$. , on the distortion of the velocity profile due to changes in density. The shape of the curves is similar to that of the curve put up by Dukler, et al, [18] (also shown in Fig. 4) in which the results from 400 critically selected data points are correlated in the form $R_{f f} v s . \lambda$. The factor $\lambda$ (Dukler's notation) is related to the density and dryness fraction by the equation

$$
\rho_{f} / \rho=(1-\gamma) / \lambda
$$

Actually Dukler's $\lambda$ is defined by him in terms of the so-called "flowing dryness fraction", $\dot{\mathrm{m}}_{f} /\left(\dot{\mathrm{m}}_{\mathrm{f}}+\dot{\mathrm{m}}_{\mathrm{g}}\right)$. There is no difference between Dukler's "flowing dryness fraction" and the dryness fraction as used in this study.

Dukler's empirical correlation for $R_{f f}$ is shown as the bold curve in Fig. 4 where we have arbitrarily set $\gamma=0$ in eq. (64) for purposes of comparison with our theory. Over the range of interest and applicability of the present theory, the correspondence between Dukler's empirical correlation and our theory using $\mathrm{m}=0.3$ in the density distribution is remarkable. In order to predict $R_{f f}$ for $\rho_{f} / \rho>100$, it would be necessary for us to incorporate assumptions about mist flow into our model. For large values of $\rho_{f} / \rho$, the function $R_{f f}$ gradually decreases, approaching the pure vapor friction factor 
behavior asymptotically.

To gain an appreciation for the effect of dryness fraction in the Dukler correlation, we recomputed his curve for two different values of $\rho_{f} / \rho_{g}$ with the aid of eq. (64) and the relation

$$
\rho_{f} / \rho=1-\gamma+\gamma\left(\rho_{f} / \rho_{g}\right)
$$

The results are shown in Fig. 5 where we have used the present theory with $\mathrm{m}=0.3$ as a basis for comparison.

An indication of the physical nature of the flow is given in Figs. 6 and 7 where the velocity and density distributions across the pipe are shown. Several profiles are shown for various values of $\rho_{f} / \rho$ on the centerline of the pipe. It can be seen that most of the variation in density occurs very close to the wa11, particularly for higher values of $\rho_{f} / \rho$ on the centerline.

\section{Summary and Conclusions}

A method is developed in this paper which calculates the two-phase flow friction factor at any state of the fluid in the pipe. The mixing-1ength theory was employed for the calculation of the Reynolds stresses in turbulent two-phase flow. The friction factors obtained this way are in good agreement with experimental data.

It is clear that the choice of the parameter $m$, or the density distribution, is rather arbitrary. Careful experimentation will be required to refine the analysis given in this study, and in particular to provide guidance in the proper selection of the parameter $m$.

\section{Acknowledgements}

This study was performed under Contract DE-AC02-79ET27225 of the Division of Geothermal Energy, U.S. Department of Energy. The authors thank 
R. J. Hanold (Los Alamos Scientific Laboratory) and C. B. McFarland (U.S.D.O.E., Washington, D.C.) for their support. Furthermore, we wish to acknowledge the fruitful discussions with other members of the research team at Brown University, notably J. Kestin, Co-Principal Investigator, Z. Bilicki and J. Mikielewicz. 
$\underline{\text { References }}$

[1] Bilicki, Z., DiPippo, R., Michaelides, E.E. and Kestin, J., "Geotherma1 Two-Phase Flow: A Selective, Annotated Guide to the Literature", Brown University Report No. GEOFLO/7, DOE/ET/27225-11, June 1980.

[2], Martine11i, R.G. and Nelson, D.B., "Prediction of Pressure Drop during Forced Circulation Boiling of Water", Trans. A.S.M.E., 70, 1948, pp. 695-702.

[3] Lockhart, R.W. and Martinelli, R.G., "Proposed Correlation Data for Isothermal Two-Phase Two Component Flow in Pipes", Chem. Eng. Prog., 45, 1949, pp. 39-48.

[4] Owens, W.L., Jr., "Two-Phase Pressure Gradient", Int. Devel. in Heat Transfer, A.S.M.E., 1961, pp. 363-368.

[5] Levy, S., "Steam Slip. Theoretical Prediction from Momentum Model", Trans. A.S.M.E., J. of Heat Transfer, 82, 1960, pp. 113-124.

[6] Zuber, N. and Hench, J., "Steady State and Transient Void Fractions of Bubbling Systems and Their Operating Limits", General Electric Company, Report No. 62GL100, 1962.

[7] Mendelson, H.D., "The Prediction of Bubble Terminal Velocities from Wave Theory", A.I.Ch.E. Journa1, 13, 1967, pp. 250-253.

[8] Griffith, P. and Wallis, G.B., "Two-Phase Slug Flow", Trans. A.S.M.E., $\mathrm{J}$. of Heat Transfer, $83,1961, \mathrm{pp}, 30.7,320$.

[9] Levy, S., "Prediction of Two-Phase Annular Flow with Liquid Entrainment", Int. J. of Heat and Mass Transfer, 9, 1966, pp. 171-188.

[10] Bankoff, S.G., "A Variable Density Single-Fluid Model for Two-Phase Flow with Particular Reference to Steam-Water Flow", Trans. A.S.M.E., J. of Heat Transfer, 82, 1960, pp. 265-152.

[11] Levy, S., "Prediction of Two-Phase Pressure Drop and Density Distribution from Mixing Length Theory", Trans. A.S.M.E., J. of Heat Transfer, 85,1963, pp. 137-152.

[12] Prandt1, L,, "Über die ausgebildete Turbulenz", Z.A.M.M. , 5, 1925, pp. 136-139. (In German)

[13] Pai, S.I., "On Turbulent Jet Mixing of Two Gases at Constant Temperature", Trans. A.S.M.E., J. of App1. Mech., 77, 1955, pp. 41-47.

[14] Schlichting, H., Boundary-Layer Theory. 7th ed., Trans1. by J. Kestin, McGraw-Hi11, New York, 1979.

[15] Pai, S.I., Viscous Flow Theory. Vo1. II: Turbulent Flow, Van Nostrand, Princeton, N.J., 1957. 
[16] von Karman, T., Mechanische Ähnlighkeit und Turbulenz. Collected Works II, 1920, pp. 337-346. (In German)

[17] Taylor, G.I., "The Transport of Vorticity and Heat Through Fluids in Turbulent Motion", Proc. Roy. Soc. (London A), 135, 1932, pp. 685-705.

[18] Duckler, A.E., Wicks, M. and Cleveland, R.G., "Frictional Pressure Drop in Two-Phase Flow. A. A Comparison of Existing Correlations for Pressure Drop and Holdup", A.I.Ch.E. Journa1, 10, 1964, pp. 38-43. 


\section{List of Symbols}

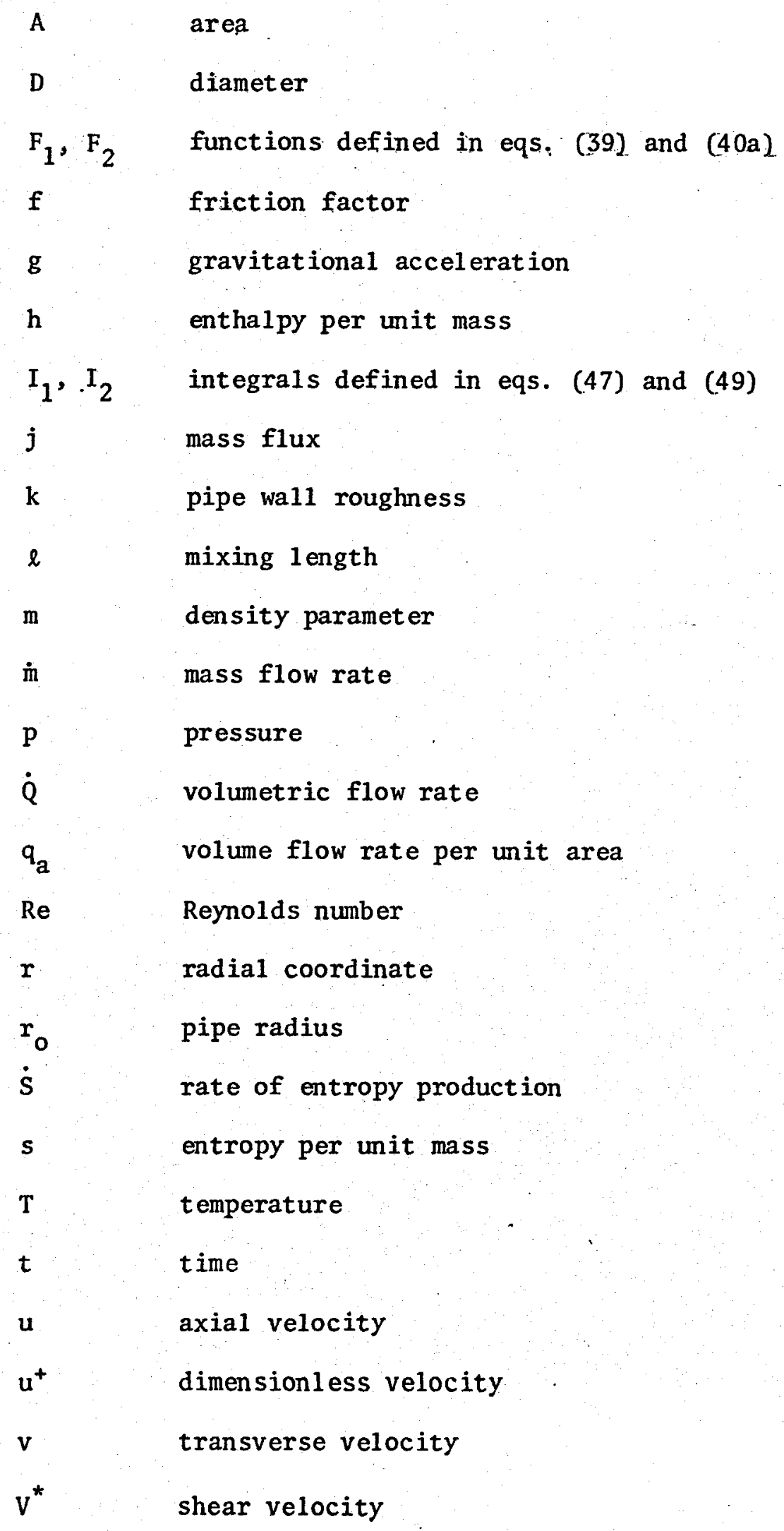




$\begin{array}{ll}x & \text { axial coordinate } \\ y & \text { transverse coordinate } \\ y_{0} & \text { thickness of laminar sublayer } \\ z & \text { gravitational coordinate }\end{array}$

Greek 1etters:

$\alpha$

density parameter

$\gamma$

dryness fraction

$n$

boundary layer coordinate

$\kappa$

mixing length constant

$\lambda$

Dukler's function, defined in eq. (64)

$\mu$

dynamic viscosity

$v$

kinematic viscosity

$\rho$

density

$\tau$

shear stress

$\tau_{w}$

wall shear stress

$\phi$

void fraction

Subscripts:

d

discharge

f

liquid phase

g

vapor phase

SP

single-phase

$\mathrm{TP}$

two-phase

$\mathbf{u}$

velocity

$\rho$

density

Superscripts:

I

variation

time average 
$-26-$

Figure Captions

Figure 1. Simple models for (a) single- and (b) two-phase flow through a circular pipe.

Figure 2. Coordinate system for pipe flow.

Figure 3. Definition of laminar sublayer thickness $y_{0}$.

Figure 4. Solution curves compared with Dukler's correlation.

Figure 5. Comparison between present theory with $m=0.3$ and Dukler's correlation with two values of $\rho_{f} / \rho_{g}$

Figure 6. Velocity profiles for $m=0.3$.

Figure 7. Density profiles for $m=0.3$. 


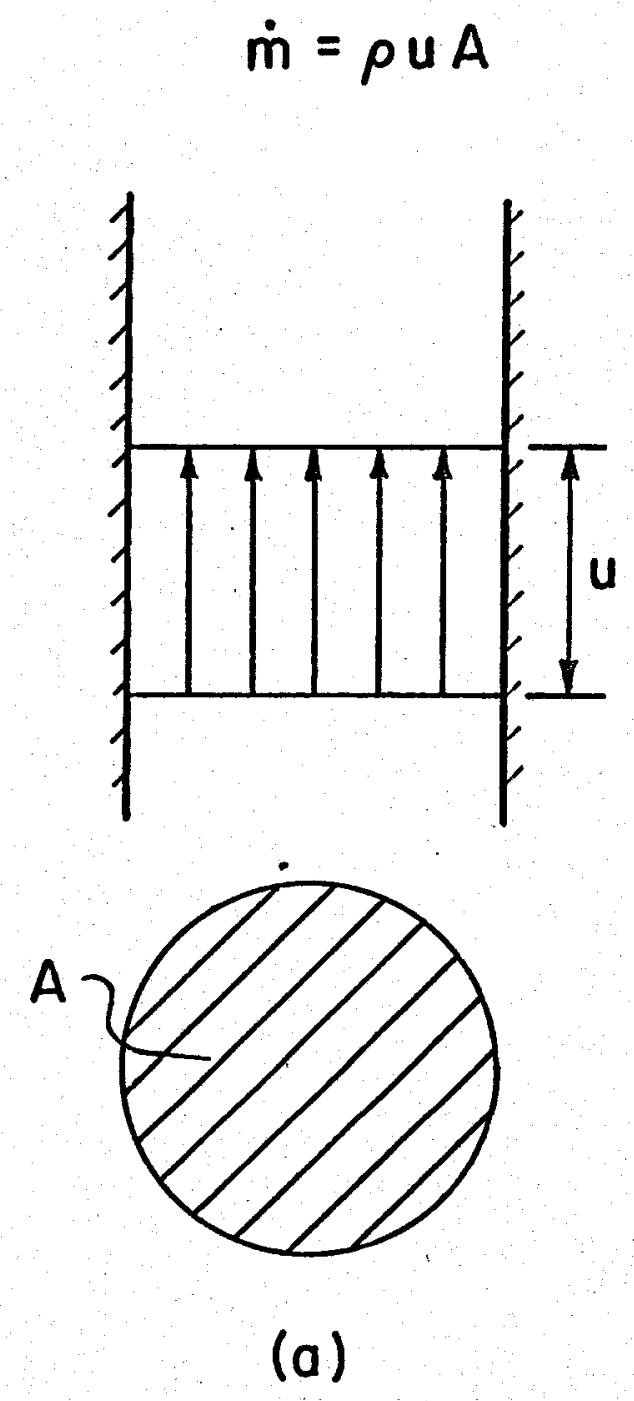

$$
\dot{m}=\rho_{g} u_{g} A \phi+\rho_{f} u_{f} A(1-\phi)
$$
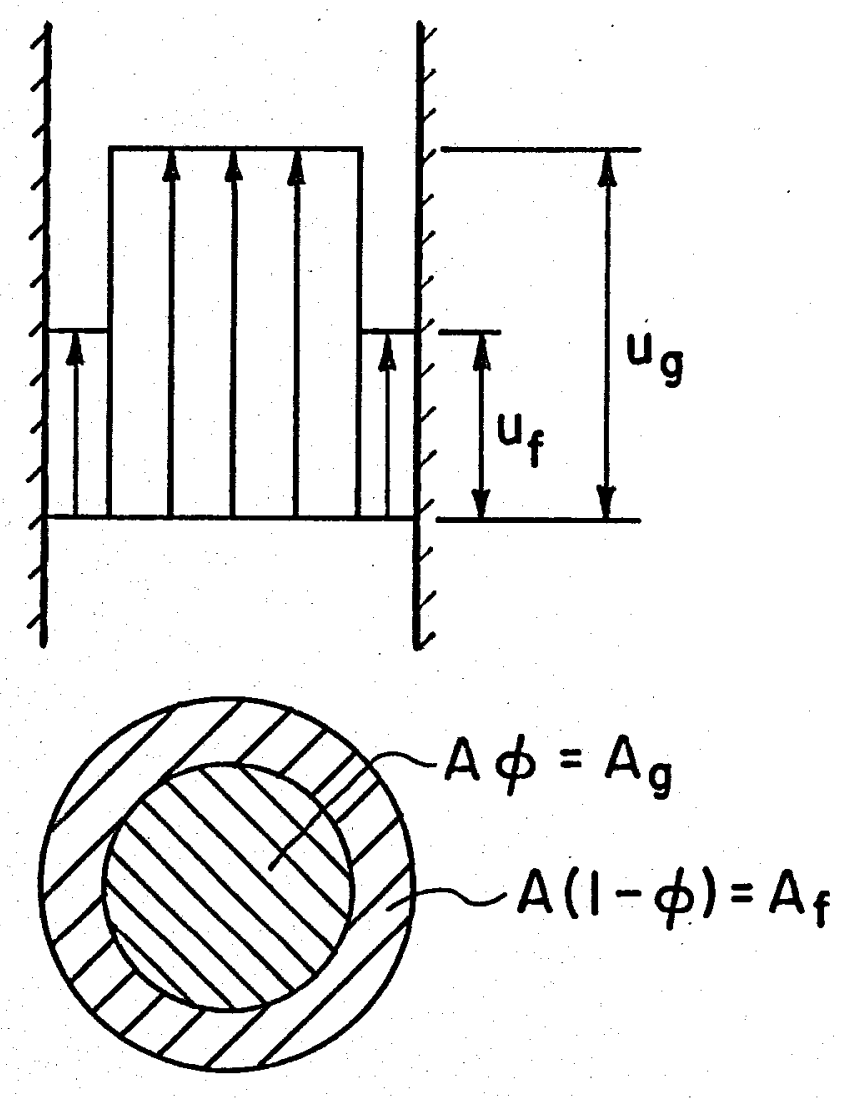

(b)

Figure 1.

Simple models for (a) single- and (b) two-phase

flow through a circular pipe 


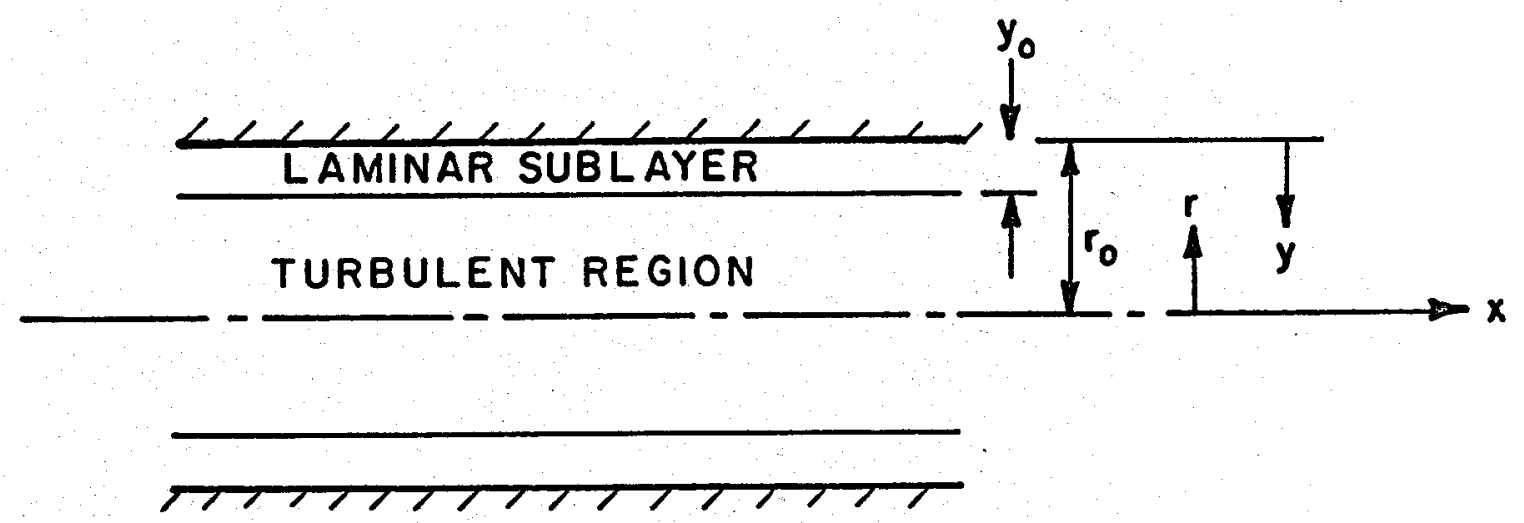

Figure 2.

Coordinate system for pipe flow 


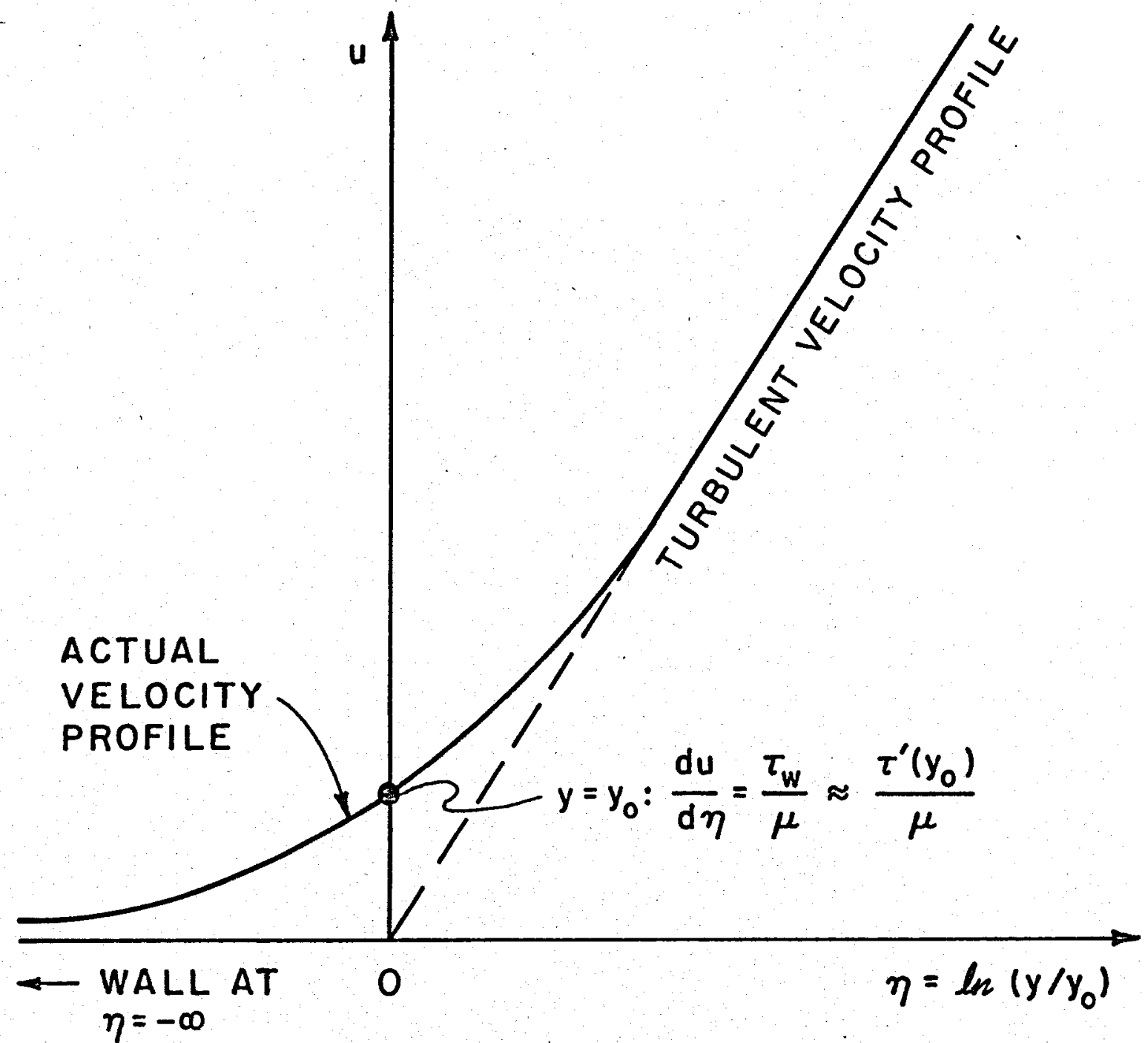

Figure 3.

Definition of laminar sublayer thickness $y_{0}$ 


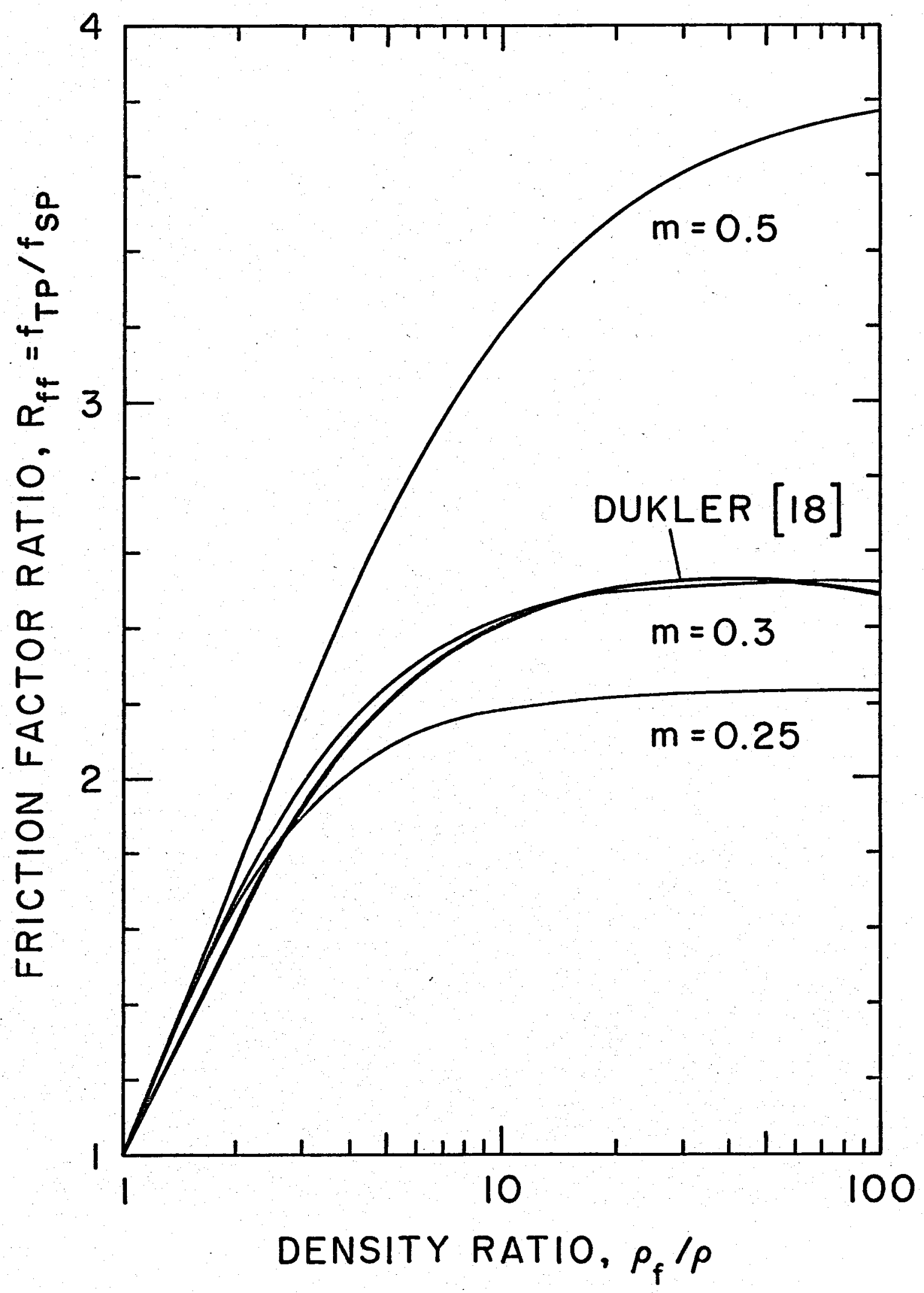

Figure 4.

Solution curves compared with Dukler's correlation 


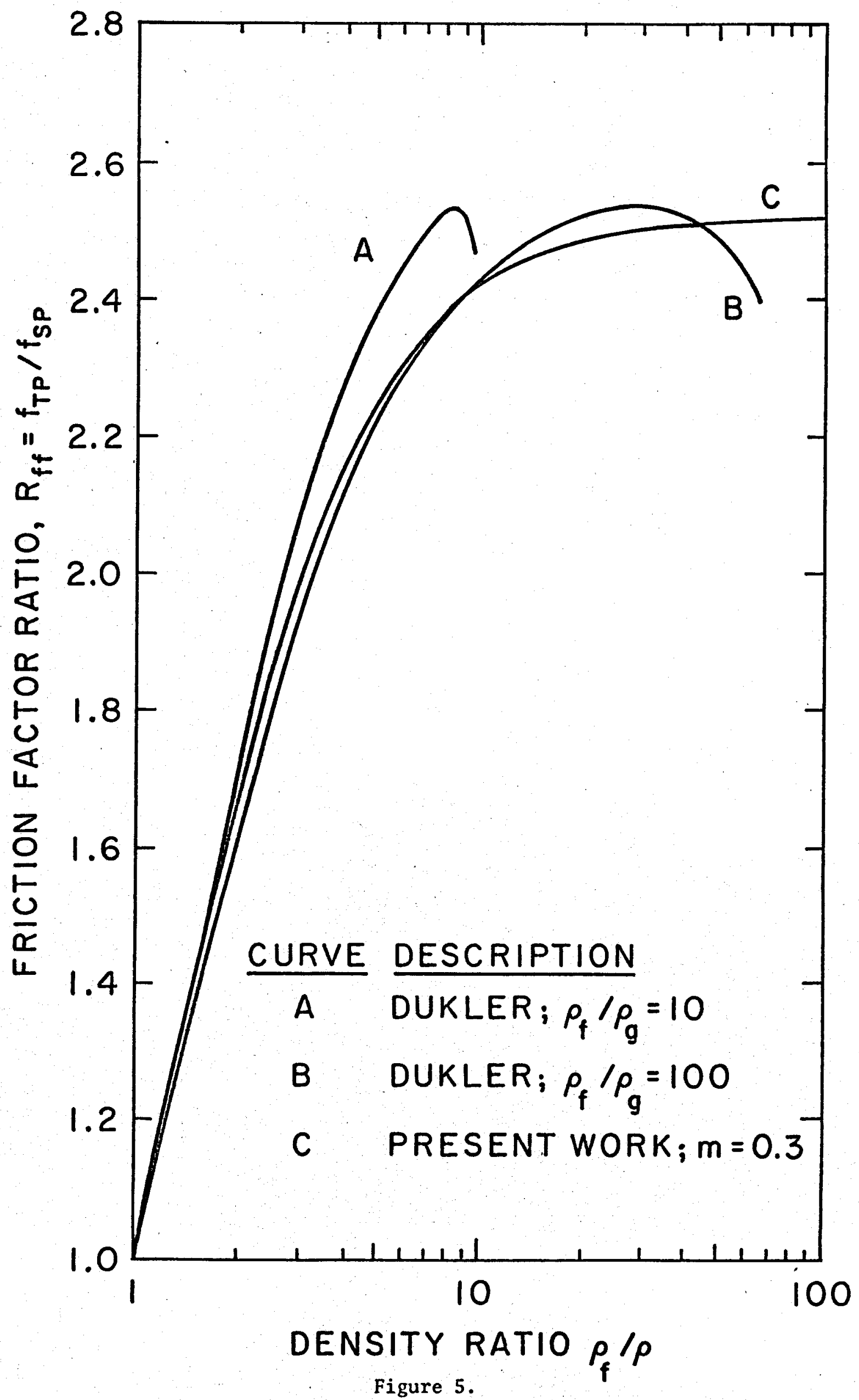

mparison between present theory with $m=0.3$ and Dukler's correlation with two values $\rho_{f} / \rho_{g}$ 


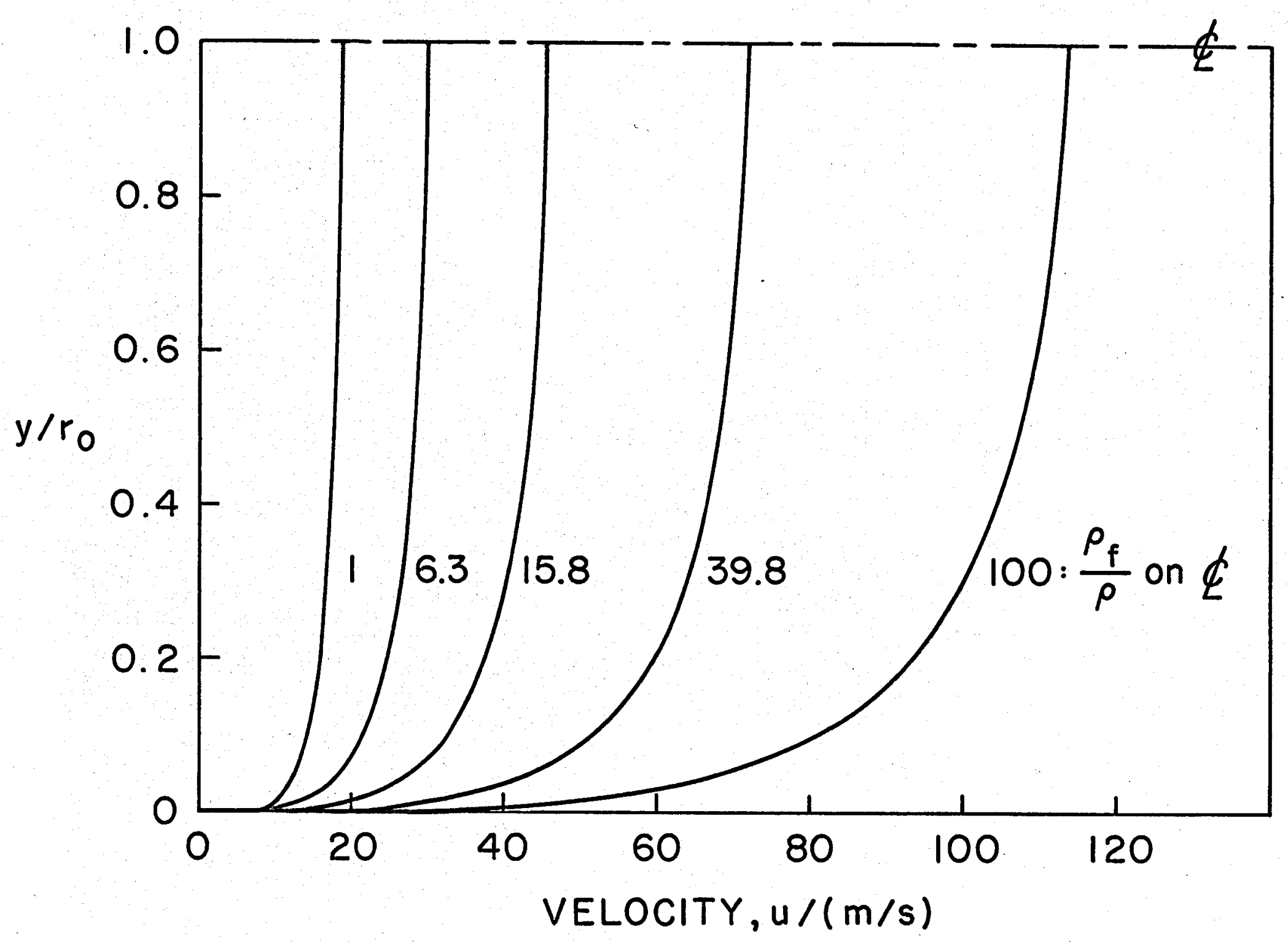

Figure 6.

Velocity profiles for $m=0.3$ 


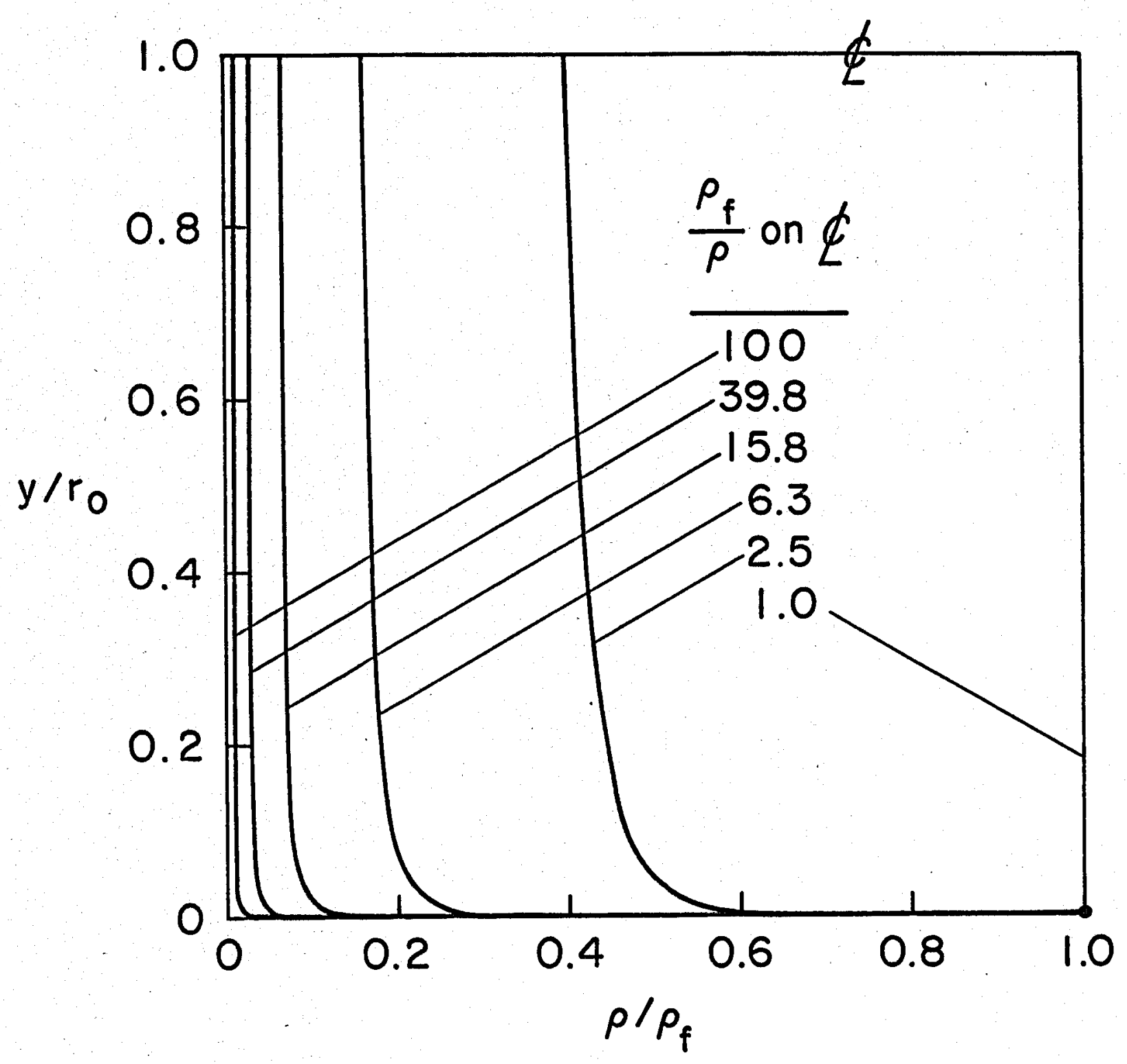

Figure 7.

Density profiles for $m=0.3$ 